\title{
Itch-Associated Response Induced by Experimental Dry Skin in Mice
}

\author{
Takayuki Miyamoto $^{1,2}$, Hiroshi Nojima ${ }^{1}$, Tomoko Shinkado ${ }^{1}$, Takashi Nakahashi ${ }^{2}$ and Yasushi Kuraishi ${ }^{1, *}$ \\ ${ }^{1}$ Department of Applied Pharmacology, Faculty of Pharmaceutical Sciences, Toyama Medical and Pharmaceutical University, \\ 2630 Sugitani, Toyama 930-0194, Japan \\ ${ }^{2}$ Ikeda Mohando Co., Ltd., Research Laboratory, 48 Jinden, Kamiichi, Toyama 930-0365, Japan
}

Received November 5, 2001 Accepted December 6, 2001

\begin{abstract}
The present study was conducted to establish a new mouse model of dry skin pruritus. The rostral back was treated daily with cutaneous application of acetone/ether (1:1) mixture (AE), water following $\mathrm{AE}$ (AEW), $1 \%$ sodium lauryl sulfate (SLS) or tape stripping (TS). On the day after 5-day treatment, although all four treatments significantly decreased stratum corneum (SC) hydration and increased transepidermal water loss (TEWL), only AEW treatment significantly increased spontaneous scratching. An increase in the frequency of TS produced the marked increase of TEWL, without significant effects on SC hydration and spontaneous scratching. In AEW-treated mice, changes in SC hydration and TEWL were marked in the initial 2-day period, while spontaneous scratching increased gradually from 3 days after starting the treatment. The degranulation of cutaneous mast cells was increased by SLS treatment but not by other treatments. There was no apparent difference in $\mathrm{AEW}$-induced spontaneous scratching between mast cell-deficient mice $\left(\mathrm{WBB}_{1} \mathrm{~F}_{1}-\mathrm{W} / \mathrm{W}^{\mathrm{V}}\right)$ and normal littermates $\left(\mathrm{WBB}^{2} \mathrm{~F}_{1}-+/+\right)$. Opioid antagonists, naloxone and naltrexone, $(1 \mathrm{mg} / \mathrm{kg}$, subcutaneously) significantly suppressed spontaneous scratching in AEW-treated mice. It is suggested that spontaneous scratching of AEW-treated mice is an itch-related response and a useful model for studying the mechanisms of dry skin pruritus.
\end{abstract}

Keywords: Scratching, Xerosis, Stratum corneum, Mast cell, Opioid antagonist

Pruritus is a common symptom in various dermatosis and/or dermatitis characterized by the dry skin, such as senile xerosis, atopic dermatitis and seasonal xerosis in winter $(1,2)$. Severe itch due to dry skin distresses most of patients with renal failure or cholestasis. Dry skin is caused by reduction of water-holding capacity, which is regulated by cutaneous barrier function, in stratum corneum. Some reports implicated skin dryness itself and/or cutaneous barrier disruption in dry skin-associated pruritus $(3,4)$, in which skin dryness is characterized by reduction of stratum corneum (SC) hydration, and cutaneous barrier disruption is characterized by increase in transepidermal water loss (TEWL). However, other reports could not relate changes in SC hydration and TEWL to pruritus $(5-7)$. Thus, the mechanisms of dry skin pruritus are unclear and effective medications for the pruritus have not been established.

The experimental model of cutaneous barrier disruption has been demonstrated by treatment with organic solution or surfactant, diet without essential fatty acid and physical disruption by tape stripping (TS) $(8-11)$. These models

*Corresponding author. FAX: +81-76-434-5045

E-mail: kuraisiy@ms.toyama-mpu.ac.jp may be mainly due to removal of lipid components in the SC such as ceramides, cholesterol and free fatty acids, which play an important role in cutaneous barrier function $(12,13)$. Additionally, treatment with organic solvent and water or exposure in the dry environment can disrupt the barrier with the loss of aqueous components, including amino acids, $\alpha$-hydroxylates, pyrrolidonecarboxylate and urea $(14,15)$. However, itch-associated responses and the mechanisms have not been investigated in these models. Thus, there is no animal model to use for the screening test of the medications for dry skin pruritus.

We have shown that injections of pruritogenic, but not algesiogenic, agents into the rostral back elicit hind-paw scratching of the injected site in mice (16). Itching and scratching of patients with pruritic diseases are inhibited by opioid antagonists $(17,18)$. Similarly, scratching behavior induced by intradermal injections of pruritogens in healthy mice and spontaneous scratching of mice with chronic dermatitis are inhibited by opioid antagonists $(19-21)$. Therefore, scratching behavior may be used as an index of the itch response.

In this study, we examined whether dry skin-like lesion induced by disruption of cutaneous barrier would increase 
scratching and whether such scratching would be affected by opioid antagonists.

\section{MATERIALS AND METHODS}

\section{Animals}

ICR mice (Japan SLC, Shizuoka) were used, except one series of experiments in which mast cell-deficient $\left(\mathrm{WBB}_{6} \mathrm{~F}_{1}-\mathrm{W} / \mathrm{W}^{\mathrm{V}}\right)$ mice and the normal littermates ( $\left.\mathrm{WBB} \mathrm{F}_{1}-+/+\right)$ (Japan SLC) were used; they were all male and 5-week-old at the start of experiments. The animals were housed in a room under controlled temperature $\left(22 \pm 2{ }^{\circ} \mathrm{C}\right)$, humidity $(55 \pm 10 \%)$ and light (light on 07:00 19:00 h). Food and water were freely available. They were used at least 7 days after purchase. Procedures for animal experiments were conducted in accordance with the Guiding Principles for the Care and Use of Laboratory Animals approved by The Japanese Pharmacological Society.

\section{Drugs}

Naloxone hydrochloride and naltrexone hydrochloride were purchased from Sigma Chemicals Co. (St. Louis, MO, USA). All other chemicals of reagent grade were from Wako Pure Chemical Industries Ltd. (Osaka).

\section{Treatment of cutaneous barrier disruption}

The hair of mice was shaved over the rostral part of the back at least 3 days before the start of the experiment. To disrupt the cutaneous barrier, we applied four kinds of treatment to the back skin. Treatment 1: cotton $(2 \times 2 \mathrm{~cm})$ soaked with a mixture of acetone and diethylether (1:1) was laid upon the shaved area for $15 \mathrm{~s}$ (AE group). Treatment 2: immediately after AE treatment, cotton soaked with distilled water was laid upon the same area for $30 \mathrm{~s}$ (AEW group), except one experiment in which the water treatment was applied for 15,30 or $60 \mathrm{~s}$. Treatment 3 : cotton soaked with $1 \%$ sodium lauryl sulfate (SLS) solution was laid upon the shaved area for $60 \mathrm{~s}$ (SLS group). The above treatments were performed twice daily (9:00 and 17:00) under ether anesthesia. For the TS group, the SC in the shaved area were peeled with adhesive cellophane tape (Nichiban Co., Ltd., Tokyo) consecutively 4 times under ether anesthesia, except one experiment in which TS was performed 4, 6 or 8 times; such treatment was repeated once daily for 5 days.

\section{Measurement of SC hydration and TEWL}

SC hydration was measured by use of Corneometer ${ }^{\circledR}$ CM825 (Courage \& Khazawa, Cologne, Germany). The amount of hydration was expressed as relative capacitance. TEWL was measured by pressing the Tewameter ${ }^{\mathbb{B}}$ TM210 (Courage \& Khazawa) against the skin for $30 \mathrm{~s}$. Each parameter was measured on the day after the last treatment for cutaneous barrier disruption (at least $14 \mathrm{~h}$ later).

\section{Behavioral observation}

Scratching of mice was observed as described previously $(16,22)$. Briefly, four mice were put individually into an acrylic box $(26 \times 18 \times 30 \mathrm{~cm})$ composed of four cells. They were acclimated to the experimental environment for at least $1 \mathrm{~h}$, and then behaviors were videotaped with experimenters kept out of the observation room in the morning. Playback served for counting the scratching of the treated area by the hind paws; the mouse generally showed several scratchings for about $1 \mathrm{~s}$ and a series of these movements was counted as one bout of scratching. Several kinds of acute stimulation of the murine skin elicit scratching, which subsides by $30-120$ min depending on the strength and kind of stimulation $(16,19,20,22-24)$. On the other hand, mice with chronic dermatitis show spontaneous scratching all day long (25). Thus, since the aim of the present study was to examine whether a decrease in cutaneous barrier would induce long-lasting itch in mice, we observed scratching of the mouse at least $14 \mathrm{~h}$ after the treatment for barrier disruption on the previous day.

\section{Administration of drugs}

Naloxone hydrochloride and naltrexone hydrochloride were dissolved in physiological saline in a concentration of $0.1 \mathrm{mg} / \mathrm{ml}$. These agents were injected subcutaneously in a volume of $0.1 \mathrm{ml}$ per body weight of $10 \mathrm{~g}(1 \mathrm{mg} / \mathrm{kg})$ into the caudal part of the back 15 min before the start of videotaping. Physiological saline was injected as the control.

\section{Histological experiments}

The skin including the treated area of rostral back was removed after euthanasia by decapitation and exsanguination. After fixation with $10 \%$ neutralized formalin for $48 \mathrm{~h}$, the skin samples were embedded in paraffin, sectioned at $2 \mu \mathrm{m}$, and stained with hematoxylin and eosin (HE) or toluidine blue. The staining was observed using a light microscopy (AX80; Olympus, Tokyo) with a CCDcamera (Axio Cam; Carl Zeiss, Jena, Germany). The thickness of epidermis was measured on microscopic images of HE-stained sections by using of image analyzing software (Winroof $^{\circledR}$; Mitani Co., Fukui).

\section{Statistics}

Values are represented as the mean and S.E.M. Statistical significance was determined with the paired $t$-test or one-way analysis of variance followed by Dunnett's multiple comparisons; differences were considered significant at $P<0.05$. 


\section{RESULTS}

\section{TEWL, SC hydration and scratching behavior}

We examined the effects of 5-day treatment with AE, AEW, SLS or TS on TEWL, SC hydration and scratching behavior. TEWL was significantly increased by all treatments examined (Fig. 1A). AEW treatment produced the greatest effects. The TEWL was not significantly different among TS, SLS and AE groups. On the contrary, SC hydration was significantly decreased by all treatments examined (Fig. 1B). AEW treatment produced the greatest effects. $\mathrm{SC}$ hydration in the AE group was lesser than those in the TS and SLS groups. AEW treatment markedly and significantly increased scratching (Fig. 1C). On the other hand, AE treatment produced slight but not significant increase in scratching, and SLS and TS treatments did not affect it (Fig. 1C).
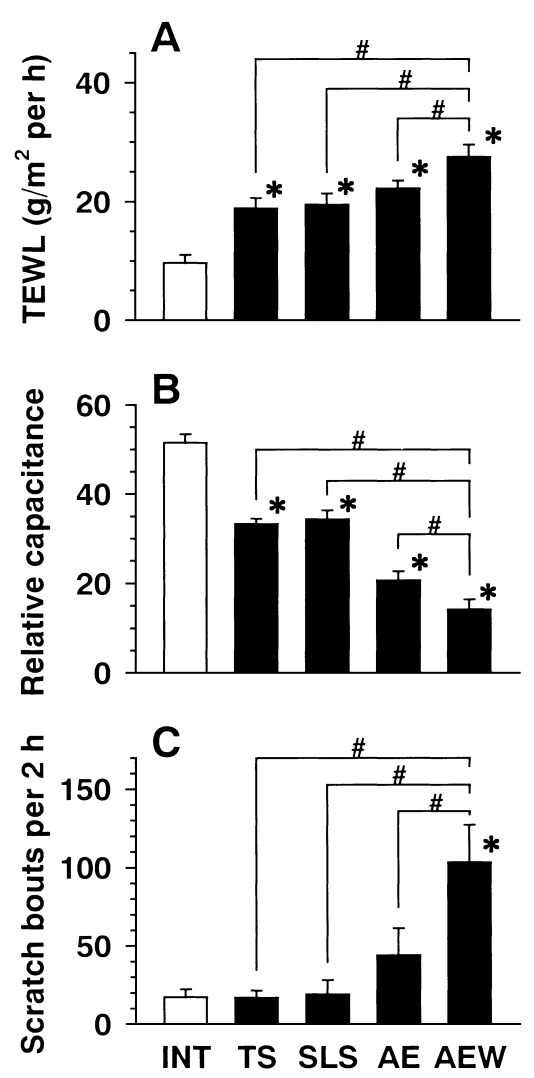

Fig. 1. Effects of various treatments for cutaneous barrier disruption on TEWL, SC hydration and scratching behavior in mice. The hair clipped-skin of the rostral part of the murine back was treated twice daily with AE, AEW or SLS, or once daily with TS for 5 days. TEWL (A), SC hydration, expressed as relative capacitance (B) and the number of scratching for $2 \mathrm{~h}$ (C) were observed on the day after the last treatment. INT represents the intact group. Values represent the mean \pm S.E.M. of 6 animals. ${ }^{*} P<0.05$ vs INT and ${ }^{\#} P<0.05$ vs AEW (Dunnett's multiple comparisons).
Histological observations of the skin

To characterize the itch-associated response following cutaneous barrier disruption, we examined the histological effects of TS, SLS, AE and AEW treatments. HE staining revealed apparent epidermal hyperplasia in the TS, SLS and AE groups, as compared with the untreated control, and the degree of hyperplasia was not apparently different between these treated groups (Figs. $2 \mathrm{~A}-\mathrm{C}$ and $3 \mathrm{~A}$ ). Infiltration of inflammatory cells in the dermis only occurred in the SLS group (Fig. 2B). On the other hand, the AEW group had marked epidermal hyperplasia, which was obviously greater that those of TS, SLS and AE groups (Figs. 2D and 3A). The AEW group also had parakeratosis and abnormally accentuated keratinization, but without infiltration of inflammatory cells in the dermis (Fig. 2D). The total number of mast cells in the skin was not significantly altered by any treatments for cutaneous barrier disruption (Fig. 3B). The number of degranulated mast cells in the skin was significantly increased in the SLS group, but not in the TS, AE and AEW groups, as compared with the untreated control (Fig. 3B).

Relationship between cutaneous barrier disruption, SC hydration and scratching in TS- and AEW-treated mice

To clarify the relationship between cutaneous barrier disruption, SC dryness and scratching behavior, we examined the effects of various AEW and TS treatments on these parameters. When the frequency of TS was increased from 4 to 8 times per day, TEWL was increased in a frequency-dependent manner (Fig. 4A). AE treatment markedly increased TEWL, which was slightly enhanced by the addition of water treatment of the duration of 15,30 or $60 \mathrm{~s}$ (Fig. 4A). The increase of TEWL after the 30-s water treatment was similar to those of 60 -s water treatment and 8-times TS treatment. Although SC hydration was slightly decreased by TS treatment, the effects were not significant nor dependent on the frequency of TS (Fig. 4B). AE treatment markedly decreased SC hydration, and the decrease was promoted by the addition of water treatment; the effect was dependent on the duration of water treatment (Fig. 4B). The number of spontaneous scratchings was slightly but not significantly increased by TS treatment (Fig. 4C). Although AE treatment was without effect on spontaneous scratching, the addition of water treatment of the duration of 15,30 or $60 \mathrm{~s}$ significantly increased it; there were no apparent differences between these three groups (Fig. 4C).

Time-dependent effects of AEW treatment on TEWL, SC hydration and scratching behavior

In this series of experiments, we examined the timedependent effects of AEW treatment on TEWL, SC hydration and scratching behavior. When AEW treatment was 

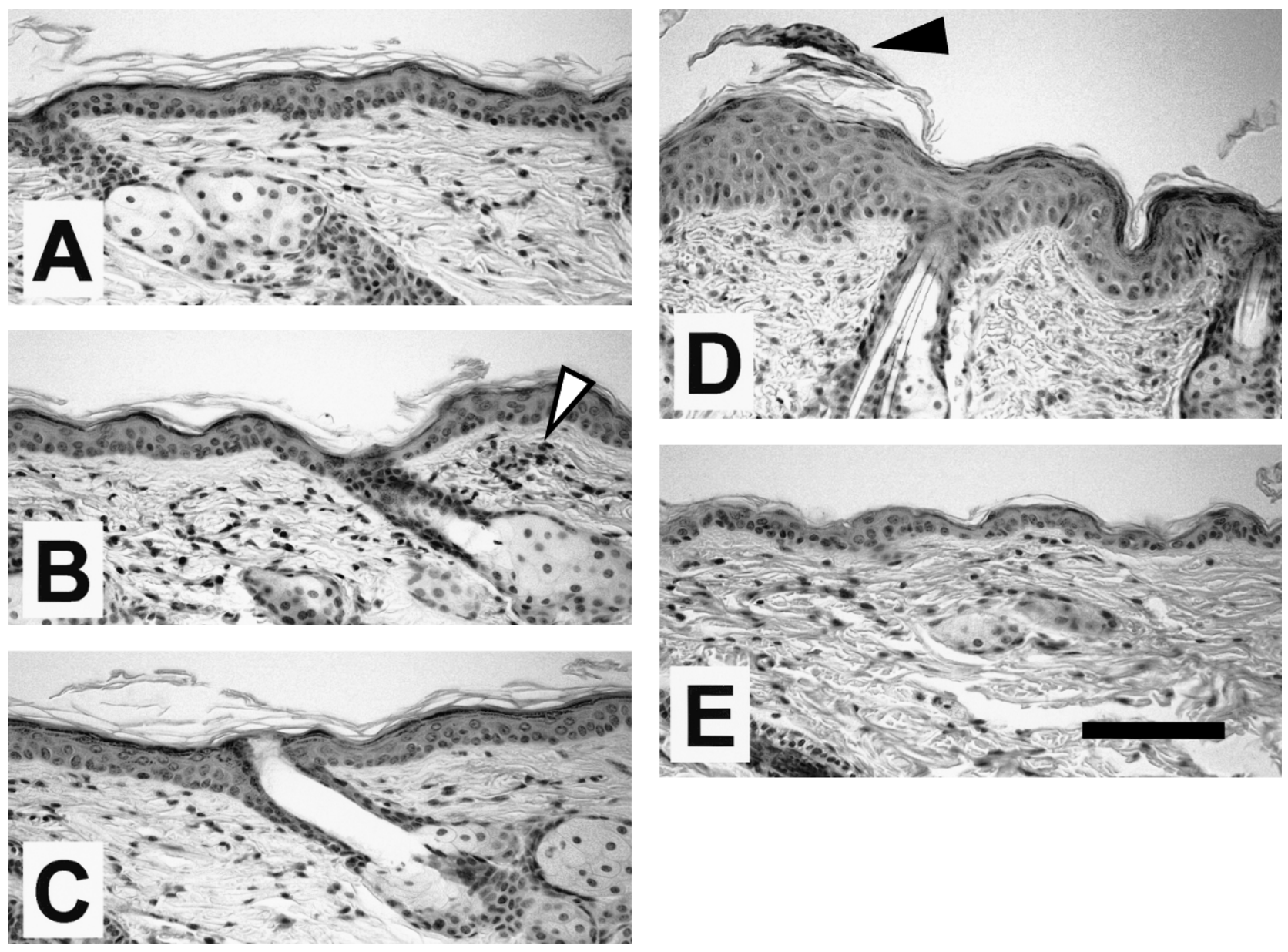

Fig. 2. Hematoxylin and eosin (HE) staining of the skin treated for barrier disruption. The murine skin was treated as mentioned in Fig. 1. The pictures represent the HE-stained sections from the skin treated with TS (A), SLS (B), AE (C) or AEW (D), or given no treatment (E). It is noteworthy that the epidermis of AEW-treated skin has apparent hyperplasia with abnormally accentuated keratinization and parakeratosis (closed arrowhead), but the dermis of AEW-treated skin is without apparent infiltration of inflammatory cells. In SLS-treated skin, there is the infiltration of inflammatory cells (open arrowhead) in the dermis. Scale bar $=100 \mu \mathrm{m}$.

repeated twice daily, TEWL was rapidly increased in the initial 2 days and then plateaued at $2.4-2.9$ fold increase (Fig. 5A). On the contrary, the SC hydration was rapidly decreased for the initial 2-day period and then was relatively constant from day 2 to day 5 (Fig. 5B). On the other hand, although scratching was not altered for 2 days, it gradually and significantly increased from day 3 to day 5 (Fig. 5C). When AEW treatment was continued until day 14 , the number of scratchings did not increase more than that of day 5 (data not shown).

Scratching induced by AEW treatment in mast celldeficient mice

When treated with AEW for 5 days, the number of scratchings was significantly increased in both mast celldeficient mice and normal littermates (Fig. 6). The number of scratching after the AEW treatment was similar between mast cell-deficient mice and normal ones.

Effects of opioid receptor antagonists on spontaneous scratching

To confirm that the scratching of AEW-treated mice was an itch-associated behavior, we examined the effects of opioid receptor antagonists on the spontaneous scratching of mice treated with AEW for 5 days. Subcutaneous injections of naloxone and naltrexone (each $1 \mathrm{mg} / \mathrm{kg}$ ) significantly suppressed the spontaneous scratching (Fig. 7).

\section{DISCUSSION}

One important finding in the present experiments is that repeated treatment to disrupt a cutaneous barrier increased scratching of the treated skin in mice. Among four kinds of treatments (TS, SLS, AE and AEW), only AEW treatment 

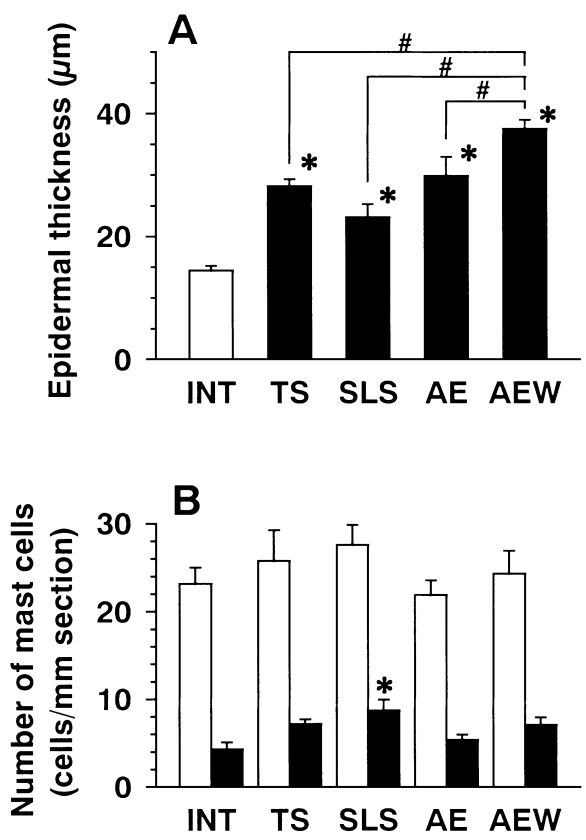

Fig. 3. Epidermal thickness and the number of mast cells in the skin treated for barrier disruption. The murine skin was treated as mentioned in Fig. 1. The skin preparations were stained with toluidine blue. A, Epidermal thickness of the intact (INT) and treated skins. B, The number of total (open columns) and degranulated (closed columns) mast cells in the skin. Values represent the mean \pm S.E.M. of 5 animals. ${ }^{*} P<0.05$ vs INT and ${ }^{\#} P<0.05$ vs AEW (Dunnett's multiple comparisons).

significantly increased spontaneous scratching. We observed behaviors at least $14 \mathrm{~h}$ after the treatment and scratching increased gradually from 3 to 5 days after the start of treatment. The results suggest that the scratching is not due to acute stimulation by AEW treatment, but instead due to the continuous changes in the function of the skin.

Spontaneous scratching after the AEW treatment was significantly suppressed by two opioid antagonists, naloxone and naltrexone. Opioid antagonists reduce itching of patients with pruritic diseases such as cholestasis, chronic urticaria and atopic dermatitis (17, 26-28). Naloxone suppresses experimental itch induced by histamine in humans (29). With regard to animals, opioid antagonists inhibit scratching elicited by intradermal injection of pruritogens such as substance $P$ and serotonin $(20,22)$ and scratching following the immediate allergic response (24). Spontaneous scratching in mice with chronic dermatitis is also suppressed by opioid antagonists (21). With these findings taken into account, the present results suggest that spontaneous scratching induced by AEW treatment is an itch-associated response. In mice, intracisternal and intrathecal injections of morphine and mu-opioid peptide receptor agonist induce scratching, but intradermal injections of opioids, including morphine and mu-opioid peptide
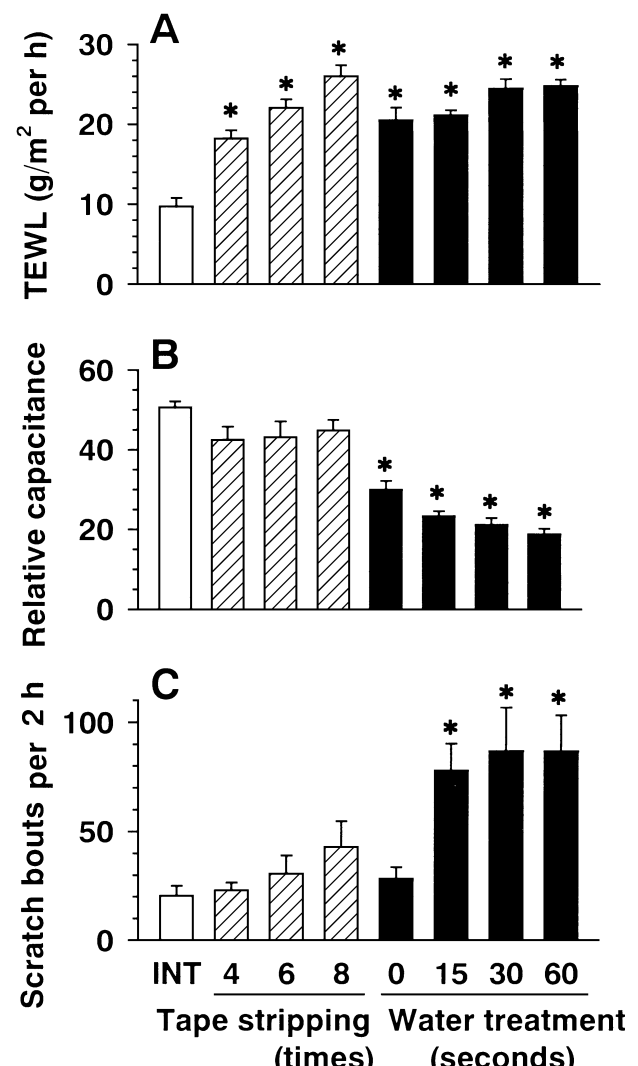

(times) (seconds)

Fig. 4. Effects of various conditions of TS and AEW treatment on TEWL, SC hydration and scratching behavior in mice. The TS and AEW treatments were given to the hair-clipped skin of the murine back. TS (hatched columns) was performed 4,6 or 8 times and such treatment was repeated once daily for 5 days. For AEWtreatment (closed columns), water treatment was applied to the clipped skin for $0,15,30$ or $60 \mathrm{~s}$ after the $15-\mathrm{s} \mathrm{AE}$ treatment. INT represents the intact group (open column). TEWL (A), SC hydration (B) and spontaneous scratching for 2-h duration (C) were observed on the day after the last treatment. Values represent the mean \pm S.E.M. of 8 animals. ${ }^{*} P<0.05$ vs intact group (Dunnett's multiple comparisons).

receptor agonist, are without effects $(30-32)$. In humans, intrathecal and epidural injections of opioid, especially morphine cause itch as a side effect, which is antagonized by opioid antagonists (for review see 33). These findings taken together suggest that opioid antagonists act on the central nervous system to inhibit the AEW-induced spontaneous scratching.

TS, SLS, AE and AEW treatments significantly increased TEWL, suggesting the disruption of the cutaneous barrier. Although AEW and 8-times TS treatments produced the greatest increase of TEWL among the treatments tested, it may be relatively mild as compared with acute disruption of the cutaneous barrier, in which TEWL increases more than tenfold generally $1 \mathrm{~h}$ after treatment $(9,34-36)$. On the other hand, in our preliminary experiment, TEWL was increased 1.5 -fold (from $9.18 \pm 1.13$ to 

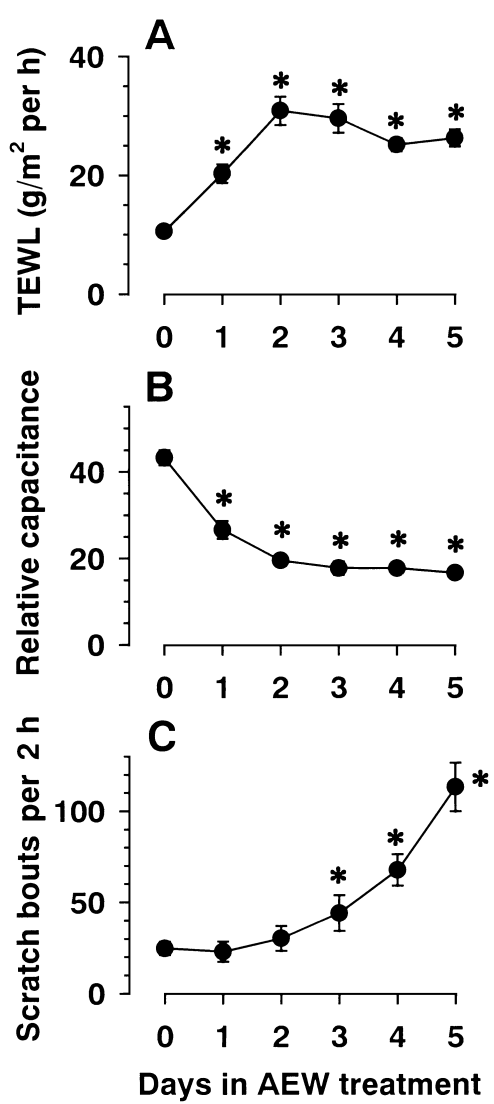

Fig. 5. Time-dependent changes in TEWL, SC hydration and scratching behavior in mice treated with AEW. The hair clipped-skin of the rostral part of the murine back was treated with AEW twice daily for 5 days. The TEWL (A), SC hydration, expressed as relative capacitance (B) and the number of scratching (C) were measured at least $14 \mathrm{~h}$ after the preceding $\mathrm{AEW}$ treatment. Values represent the mean \pm S.E.M of 8 (A), 12 (B) or 7 (C) animals. ${ }^{*} P<0.05$ vs day 0 (Dunnett's multiple comparisons).

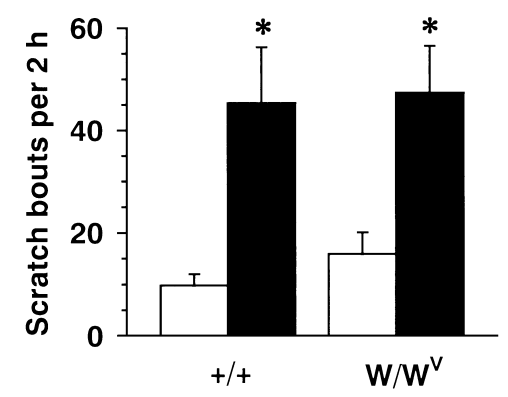

Fig. 6. Scratching after AEW treatment in mast cell-deficient mice. Mast cell-deficient $\mathrm{WBB} 6 \mathrm{~F}_{1}-\mathrm{W} / \mathrm{W}^{\mathrm{V}}$ mice $\left(\mathrm{W} / \mathrm{W}^{\mathrm{V}}\right)$ and $\mathrm{WBB} 6 \mathrm{~F}_{1}{ }^{-+} /+$ normal littermates $(+/+)$ were given AEW treatment for 5 days, as mentioned in the Materials and Methods. Open columns, before treatment; closed columns, after AEW treatment. Values represent the mean \pm S.E.M. of 8 animals. ${ }^{*} P<0.05$ vs control in each group (paired $t$-test).

$14.08 \pm 1.92 \mathrm{~g} / \mathrm{m}^{2}$ per $\left.\mathrm{h}, \mathrm{n}=4\right) 1 \mathrm{~h}$ after AEW treatment. In addition, TEWL was increased around threefold after

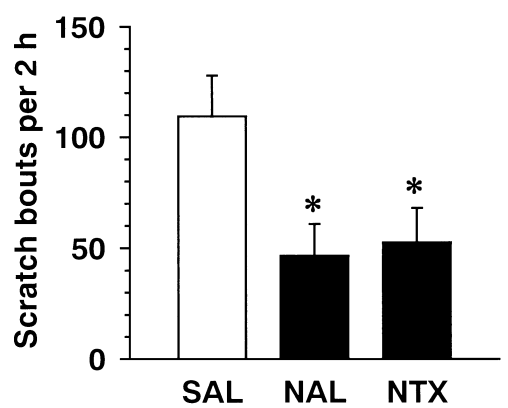

Fig. 7. Suppression by naloxone and naltrexone of scratching in AEW-treated mice. The skin was treated with AEW for 5 days and naloxone (NAL) and naltrexone (NTX) were injected subcutaneously at a dose of $1 \mathrm{mg} / \mathrm{kg}$. Behaviors were observed for $2 \mathrm{~h}$ since $15 \mathrm{~min}$ after antagonist injection. SAL, mice given saline. Values represent the mean \pm S.E.M of 8 animals. ${ }^{*} P<0.05$ vs SAL (Dunnett's multiple comparisons).

repeated AEW treatment. The results that AEW treatment produced a marked increase in TEWL and spontaneous scratching raise the possibility that the hypofunction of cutaneous barrier was associated with an increase in spontaneous scratching. TEWL rapidly increased in the first 2 days and then did not increase any more, while spontaneous scratching gradually increased from day 3 . Therefore, the disruption of cutaneous barrier may be an indirect cause of scratching; in other words, the lasting barrier disruption may produce pruritogen(s) or increase the excitability of itch-signaling primary afferents. Interestingly, although the more severe conditions of TS treatment and AEW treatment produced similar increase in TEWL, but TS treatment did not significantly increase the spontaneous scratching. Thus, the disruption of the cutaneous barrier may not be a sufficient condition to cause an increase in spontaneous scratching.

Although TS, SLS, AE and AEW treatments decreased SC hydration, AEW treatment produced the greatest effect. Therefore, the results that only AEW treatment increased spontaneous scratching raise the possibility that reduced $\mathrm{SC}$ hydration is associated with an increase in spontaneous scratching. Although the more severe conditions of TS treatment increased TEWL, they did not exert marked influence on SC hydration (relative capacitance of the skin) and spontaneous scratching. The results suggest that dry skin is a more important cause of scratching than cutaneous barrier disruption. Thus, AEW may be the suitable method to develop xerosis-associated scratching in mice.

Repeated treatment with acetone or TS has been shown to cause epidermal hyperplasia (35). Similarly, in the present study, all four treatments examined resulted in substantial epidermal hyperplasia. However, the AEW treatment exerted the most marked effect. In addition, only the AEW treatment induced apparent parakeratosis. In 
contrast, only the SLS treatment induced apparent infiltration of inflammatory cells and edema in dermis without increase of spontaneous scratching. These results suggest that, AEW treatment produced the greatest proliferative effect on epidermis without a typical dermal inflammation.

In clinical cases, $\mathrm{H}_{1}$ histamine receptor antagonists, major antipruritic agents, are often ineffective against dry skin pruritus. On the other hand, the degranulation of mast cells is observed $48 \mathrm{~h}$ after acetone treatment during exposure to a dry environment (11). Histamine, a mast cell mediator, was claimed to be involved in development of the epidermal hyperplasia through activation of $\mathrm{H}_{1}$ and $\mathrm{H}_{2}$ histamine receptors (37). These findings raise the possibility that increase in the number and/or degranulation of mast cells were involved in the spontaneous scratching after the AEW treatment. However, in the present experiment, only SLS treatment increased the degranulation of mast cells $14-18 \mathrm{~h}$ after the last treatment, and AEW treatment (as well as AE and TS treatments) did not affect the number and degranulation of mast cells in the treated skin. In addition, the AEW treatment increased spontaneous scratching in mast cell-deficient mice as well as the control ones. Therefore, mast cells may not be involved in the spontaneous scratching after the AEW treatment.

The mechanisms by which AEW treatment induced spontaneous scratching is unclear. We have shown that intradermal injections of several endogenous substances such as histamine, substance $\mathrm{P}$, serotonin and leukotriene $\mathrm{B}_{4}$ elicit itch-associated responses in mice $(19,20,22,23)$. Since mast cells may not be involved in AEW-induced spontaneous scratching, it is suggested that the mast cell mediator histamine is not involved in this scratching. We are going to examine the involvement of the other pruritogenic mediators in this scratching. In preliminary experiments, we found that there were many nerve fibers in the thickened epidermis, although in the superficial layers of normal skin, nerve fibers were mainly distributed in the dermal region close to the epidermis (T. Miyamoto et al., unpublished observation). The increased distribution of nerve fibers in the thickened epidermis is also apparent in patients with pruritic disease such as atopic dermatitis and chronic renal failure $(38,39)$. Thus, although further studies are needed, it is possible that increase in nerve fibers in the epidermis is at least partly involved in the AEW-induced spontaneous scratching.

In conclusion, repeated AEW treatment induced spontaneous scratching, which may be itch-associated response. Skin dryness, although an indirect cause, may be more important for the induction of pruritus than cutaneous barrier disruption. This murine model may be useful for the study of the mechanisms of dry skin-induced itching and screening of agents effective against xerosis-associated pruritus.

\section{REFERENCES}

1 Di Nardo A, Wertz P, Giannetti A and Seidenari S: Ceramide and cholesterol composition of the skin of patients with atopic dermatitis. Acta Derm Venereol 78, 27 - 30 (1998)

2 Thaipisuttikul Y: Pruritic skin diseases in elderly. J Dermatol 25, 153 - 157 (1998)

3 Long CC and Marks R: Stratum corneum changes in patients with senile pruritus. J Am Acad Dermatol 27, 560 - 564 (1992)

4 Morton CA, Lafferty M, Hau C, Henderson I, Joens M and Lowe JG: Pruritus and skin hydration during dialysis. Nephrol Dial Transplant 11, 1769 - 1770 (1996)

5 Deleixhe-Mauhin F, Pierard-Franchimont C, Krezinski JM, Rorive $\mathrm{G}$ and Pierard GE: Biometrological evaluation of the stratum corneum texture in patients under maintenance hemodialysis. Nephron 64, 110 - 113 (1993)

6 Ostlere LS, Taylor C, Baillod R andWright S: Relationship between pruritus, transepidermal water loss, and biochemical markers of renal itch in hemodialysis patients. Nephrol Dial Transplant 9, 1302 - 1304 (1994)

7 Kato A, Hamada M, Maruyama T, Maruyama Y and Hishida A: Pruritus and hydration state of stratum corneum in hemodialysis patients. Am J Nephrol 20, 437 - 442 (2000)

8 Elias PM, Brown BE and Ziboh VA: The permeability barrier in essential fatty acid deficiency: evidence for a direct role for linoleic acid in barrier function. J Invest Dermatol 74, 230 - 233 (1980)

9 Grubauer G, Feingold KR and Elias PM: Relationship of epidermal lipogenesis to cutaneous barrier function. J Lipid Res 28, 746 - 752 (1987)

10 Wood LC, Jackson SM, Elias PM, Grunfeld C and Feingold KR: Cutaneous barrier perturbation stimulates cytokine production in the epidermis of mice. J Clin Invest 90, 482 - 487 (1992)

11 Denda M, Sato J, Tsuchiya T, Elias PM and Feingold KR: Low humidity stimulates epidermal DNA synthesis and amplifies the hyperproliferative response to barrier disruption: implication for seasonal exacerbations of inflammatory dermatoses. J Invest Dermatol 111, 873 - 878 (1998)

12 Elias PM: Epidermal lipids, barrier function, and desquamation. J Invest Dermatol 80, 44S - 49S (1983)

13 Grubauer G, Feingold KR, Harris RM and Elias PM: Lipid content and lipid type as determinants of the epidermal permeability barrier. J Lipid Res 30, 89 - 96 (1989)

14 Jokura Y, Ishikawa S, Tokuda H and Imokawa G: Molecular analysis of elastic properties of the stratum corneum by solidstate ${ }^{13} \mathrm{C}$-nuclear magnetic resonance spectroscopy. J Invest Dermatol 104, 806 - 812 (1995)

15 Sato J, Katagiri C, Nomura J and Denda M: Drastic decrease in environmental humidity decreases water-holding capacity and free amino acid content of the stratum corneum. Arch Dermatol Res 293, 477 - 480 (2001)

16 Kuraishi Y, Nagasawa T, Hayashi K and Satoh M: Scratching behavior induced by pruritogenic but not algesiogenic agents in mice. Eur J Pharmacol 275, 229 - 233 (1995)

17 Bergasa NV, Talbot TL, Alling DW, Schmitt JM, Walker EC, Baker BL, Korenman JC, Park Y, Hoofnagle JH and Jones EA: A controlled trial of naloxone infusions for the pruritus of chronic cholestasis. Gastroenterology 102, 544 - 549 (1992)

18 Sullivan JR and Watson A: Naltrexone: a case report of pruritus from an antipruritic. Australas J Dermatol 38, 196 - 198 (1997) 
19 Andoh T, Nagasawa T, Satoh M and Kuraishi Y: Substance P induction of itch-associated response mediated by cutaneous $\mathrm{NK}_{1}$ tachykinin receptors in mice. J Pharmacol Exp Ther 286, 1140 - 1145 (1998)

20 Yamaguchi T, Nagasawa T, Satoh M and Kuraishi Y: Itchassociated response induced by intradermal serotonin through 5- $\mathrm{HT}_{2}$ receptors in mice. Neurosci Res 35, 77 - 83 (1999)

21 Yamaguchi T, Maekawa T, Nishikawa Y, Nojima H, Kaneko M, Kawakita T, Miyamoto T and Kuraishi Y: Characterization of itch-associated responses of NC mice with mite-induced chronic dermatitis. J Dermatol Sci 25, 20 - 28 (2001)

22 Andoh $\mathrm{T}$ and Kuraishi $\mathrm{Y}$ : Intradermal leukotriene $\mathrm{B}_{4}$, but not prostaglandin $E_{2}$, induces itch-associated responses in mice. Eur J Pharmacol 353, 93 - 96 (1998)

23 Maekawa T, Nojima $\mathrm{H}$ and Kuraishi Y: Itch-associated responses of afferent nerve innervating the murine skin: different effects of histamine and serotonin in ICR and ddY mice. Jpn J Pharmacol 84, 462 - 466 (2000)

24 Ohtsuka E, Kawai S, Ichikawa T, Nojima H, Kitagawa K, Shirai Y, Kamimura K and Kuraishi Y: Roles of mast cell and histamine in mosquito bite-induced allergic itch-associated responses in mice. Jpn J Pharmacol 86, 97 - 105 (2001)

25 Tohda C, Yamaguchi T and Kuraishi Y: Increased expression of mRNA for myocyte-specific enhancer binding factor (MEF) 2C in the cerebral cortex of the itching mouse. Neurosci Res 29, $209-215$ (1997)

26 Summerfield JA: Naloxone modulates the perception of itch in man. Br J Clin Pharmacol 10, 180 - 183 (1980)

27 Monroe EW: Efficacy and safety of nalmefene in patients with severe pruritus caused by chronic urticaria and atopic dermatitis. J Am Acad Dermatol 21, 135 - 136 (1989)

28 Bergasa NV, Alling DW, Talbot TL, Swain MG, Yurdaydin C, Turner ML, Schmitt JM, Walker EC and Jones EA: Effects of naloxone infusions in patients with the pruritus of cholestasis. A double-blind, randomized, controlled trial. Ann Int Med 123, $161-167$ (1995)

29 Bernstein JE, Swift RM, Soltani K and Lorincz AL: Antipruritic effect of an opiate antagonist, naloxone hydrochloride. J Invest Dermatol 78, $82-83$ (1982)

30 Tohda C, Yamaguchi T and Kuraishi Y: Intracisternal injection of opioids induces itch-associated responses through $\mu$-opioid receptors in mice. Jpn J Pharmacol 74, 74 - 77 (1997)

31 Yamaguchi T, Kitagawa $\mathrm{K}$ and Kuraishi Y: Itch-associated response and antinociception induced by intracisternal endomorphins in mice. Jpn J Pharmacol 78, 337 - 343 (1998)

32 Kuraishi $\mathrm{Y}$, Yamaguchi $\mathrm{T}$ and Miyamoto $\mathrm{T}$ : Itch-scratch responses induced by opioids through central mu opioid receptors in mice. J Biomed Sci 7, $248-252$ (2000)

33 Ballantyne JC, Loach $\mathrm{AB}$ and Carr DB: Itching after epidural and spinal opiates. Pain 33, $149-160$ (1988)

34 Feingold KR, Mao-Qiang M, Menon GK, Cho SS, Brown BE and Elias PM: Cholesterol synthesis is required for cutaneous barrier function in mice. J Clin Invest 86, 1738 - 1745 (1990)

35 Denda M, Wood LC, Emami S, Calhoun C, Brown BE, Elias PM and Feingold KR: The epidermal hyperplasia associated with repeated barrier disruption by acetone treatment or tape stripping cannot be attributed to increased water loss. Arch Dermatol Res 288, 230 - 238 (1996)

36 Harris IR, Farrell AM, Grunfeld C, Holleran WM, Elias PM and Feingold KR: Permeability barrier disruption coordinately regulates mRNA levels for key enzymes of cholesterol, fatty acid, and ceramide synthesis in epidermis. J Invest Dermatol 109, 783 - 787 (1997)

37 Ashida Y, Denda M and Hirao T: Histamine H1 and H2 receptor antagonists accelerate skin barrier repair and prevent epidermal hyperplasia induced by barrier disruption in a dry environment. J Invest Dermatol 116, 261 - 265 (2001)

38 Urashima R and Mihara M: Cutaneous nerves in atopic dermatitis. Virchows Arch 432, $363-370$ (1998)

39 Johansson O, Hilliges M and Ståhle-Bäckdahl M: Intraepidermal neuron-specific enolase (NSE)-immunoreactive nerve fibers: evidence for sprouting in uremic patients on maintenance hemodialysis. Neurosci Lett 99, 281 - 286 (1989) 